\title{
Effects of an Intervention in Active Strategies for Text Comprehension and Recall
}

\author{
$M^{a}$ Rosa Elosúa', Juan A. García-Madruga', Francisco Gutiérrez ${ }^{1}$, \\ Juan Luis Luque ${ }^{2}$, and Milagros Gárate ${ }^{3}$ \\ ${ }^{1}$ Open University (U.N.E.D.) \\ ${ }^{2}$ University of Málaga \\ ${ }^{3}$ University of Cantabria
}

The aim of this study was to investigate the effects of an intervention program to promote active text-processing strategies (main-idea identification and summarization) at two developmental levels (12- and 16-year-olds). The independent variables were training condition (experimental and control) and school level ( $7^{\text {th }}$ and $10^{\text {th }}$ grades). Several measures were taken as dependent variables: reading span, reading time, construction of macrostructure, and structural recall. The hypothesis claimed that training would increase comprehension and recall significantly. Furthermore, as a result of the training program a reduction in developmental differences in the experimental groups at posttest was also expected. Results supported the predictions, showing a significant improvement in the experimental groups' reading comprehension and recall. These results are discussed in terms of the importance of active and self-controlled strategies for text comprehension and recall.

Key words: main-idea identification, main-idea summary, reading span, macrostructure, intervention

\begin{abstract}
El objetivo de este estudio fue investigar los efectos de un programa de intervención para promover estrategias activas de procesamiento de textos (identificación de la idea principal y resumen), en dos niveles de desarrollo evolutivo (12 y 16 años). Las variabies independientes fueron la condición de entrenamiento (experimental y control) y el nivel escolar ( $7^{\circ} \mathrm{EGB}$ y $2^{\mathrm{Q}}$ BUP). Como variables dependientes se utilizaron varias medidas: la amplitud lectora, tiempo de lectura, construcción de la macroestructura y recuerdo estructural. Las hipótesis predecian que el entrenamiento aumentaría de manera significativa la comprensión y el recuerdo. Además, como resultado del programa de entrenamiento, se esperaba también una disminución en las diferencias evolutivas en los grupos experimentales en el postest. Los resultados confirmaron las predicciones mostrando una mejora significativa en la comprensión y recuerdo de los grupos experimentales. Estos resultados se interpretaron en términos de la importancia de las estrategias activas y de autocontrol en la comprensión y recuerdo de textos.

Palabras clave: identificación de la idea principal, resumen. amplitud lectora, macroestructura, intervención
\end{abstract}

This study was supported by the Centro de Investigación y Documentación Educativa (CIDE, 1992/1995).

We should like to thank the teachers and students from the Colegio La Salle (Madrid) for their collaboration.

Correspondence concerning this article should be addressed to María Rosa Elosúa, Univerșidad Nacional de Educación a Distancia (UNED). Departamento de Psicología Básica I. Ciudad Universitaria, s/n. 28040 Madrid (Spain). Fax: 91398 7972. E-mail: melosua@psi.uned.es 
The process of reading comprebension implies not only the construction of a semantic representation of the text (textbase), but also a mental representation integrated with the reader's prior knowledge structures (situation model) (see Kintsch, 1998). Current theories about text comprehension (Britton \& Graesser, 1996; van Oostendorp \& Goldman, 1999) have stressed the importance of active processing during reading in order to achieve this semantic representation. The key idea is that comprehension not only depends on the information from the rext, but also, essentially, on the participant's knowledge, which guides his or her strategy towards the text. Active processing is demanding and effective because the reader's prior knowledge structures are enriched and integrated.

This active reading process involves the working memory capacity. As some theorists have suggested, working mentory plays an important role in storing the intermediate and final products of readers' computations as they construct and integrate the semantic representation from a text (Ericsson \& Kintsch, 1995; Gathercole \& Baddeley, 1993; Just \& Carpenter, 1992). Among different working memory measures used, some studies indicate that the reading span seems to be appropriate because it correlates well with reading comprehension performance (Cantor, Engle, \& Hamilton, 1991; Daneman \& Carpenter, 1980; De Beni, Palladino, Pazzaglia, \& Cornoldi, 1998).

Regarding the semantic representation of the text (Kintsch \& van Dijk, 1978; van Dijk \& Kintsch, 1983; Kintsch, 1988 , 1998 ), within the framework of the theory proposed by Kintsch, a distinction between the text microstructure and macrostructure is established. The former is the local structure of the text, the information contained in each of the text sentences and its integration into the participant's long-term memory. The macrostructure of a text consists of a hierarchy of propositions representing its overall structure, derived from the microstructure. Thus, the macrostructure can be represented as a propositional format (e.g., macropropositions that summarize the general idea).

According to this comprehension model, the construction of these macropropositions is carried out by applying certain macrorules that allow the information contained in the text to be reduced and organized. These macrorules are selection, generalization, and construction. An important feature in the application of these macrorules is that the difficulty is closely related to the reader's previous knowledge stored in the memory, and the more or less active use made of it. Whereas the selection macrorule basically requires a process of recognition, the generalization macrorule is more complex because it is based on a logical relation of inclusion. Construction is an even more complex cognitive operation, as it requires relationships of various types to be determined from among the elements and ideas of the text.

Some studies have shown that, using intervention programs, it is possible to increase the use of knowledge of the text structure as a comprehension strategy and as a basis for self-regulation of learning (León \& Carretero, 1995; Piolat \& Roussey, 1996). The relevance of this dimension of self-regulation, or metacognitive dimension, has become evident, especially from the developmental perspective. On the one hand, various studies indicate that the developmental differences in reading comprehension and text recall are not only influenced by age-related structural aspects, but especially by development of a metacognitive nature (Baker \& Brown, 1984; Kurtz, 1991; Piolat \& Roussey, 1996). On the other hand, it should be taken into account that one of the main achievements of comprehension is to obtain that same self-regulation of the comprehension process and of learning (Baumann, 1990; Brown \& Palincsar, 1984; Volet, 1997).

We present a study to test an intervention program aimed at improving some basic text-processing skills within a developmental perspective, along the lines of previous research (García Madruga, Martín Cordero, Luque, \& Santamaria, 1995). Thus, unlike our previous work-based on developing reading-comprehension skills in 17-year-old participants- - the present study was conducted with two different age groups: $7^{\text {th }}$ graders (12 year olds) and $10^{\text {th }}$ graders (16 year olds).

In this context of active text-processing strategies, the purpose of this study is to make a contribution from both the theoretical and practical points of view. At the theoretical level, focus was on the process of macrostructure construction and text recall, based on acquisition and active use of the selection and generalization macrorules, as well as on the metacognitive strategy of participants" selfassessment of their degree of comprehension. We were also interested in these processes from their developmental viewpoint due to the possible educational implications for the school-age levels involved, along the lines of previous developmental studies that revealed significant improvement in reading skills in the age group studied (García Madruga, Gárate, Elosúa, Luque, \& Gutiérrez, 1997).

We therefore decided that, although the general aims and even the basic contents of the intervention could be the same for $7^{\text {th }}$ as for $10^{\text {th }}$ graders, given the differences in reading skills between the two age groups, it would be necessary to adapt the intervention program to the characteristics and development level of each of them. As pointed out (Kintsch \& Kintsch, 1995; McKeown, Beck, Sinatra, \& Loxterman, 1992; McNamara \& Kintsch, 1996; McNamara, Kintsch, Songer, \& Kintsch, 1996), a key aspect in promotion of teaching and use of active strategies during reading is to involve participants in appropriate tasks. For instance, the task of training participants in the selection and generalization of main-idea identification requires them not only to pay attention to text but also to link the more meaningful ideas, ordering, and as a result, identifying the main idea. This task may also be carried out by younger participants ( $7^{\text {th }}$-grade students) during the training program, so that they are capable of overcoming the first difficulties 
and continuing to improve their comprehension, using it appropriately. With $10^{\text {th }}$-grade students, it is also possible to adapt the relevant main-idea identification strategy because we can always use longer and more complex texts.

The aim of our program was to teach students how to jdentify and achieve a generalized and flexible use of mainidea identification strategies (by applying the macrorules of selection and generalization), and how to draw up outlines based on the main ideas that they had previously identified We also tried to ensure that the entire instruction had a metacognitive approach, insofar as it was designed so that the participants not only learned the various strategies, but so they also became aware of when and how to apply them adequately, regardless of the reference contents. In addition, we also specifically tried to influence a metacognitive aspect of particular importance: the self-evaluation of the results of the task.

Thus, in the intervention carried out, we have attempted to integrate the three basic aforementioned components direct instruction, modeling, and practice- into this metacognitive approach. We therefore organized the procedure according to three recurrent phases, relative to each component: (a) detailed description of the strategy to be used and how and when to use it, with a concrete example, if necessary (Baumann, 1990; Roehler \& Duffy, 1984); (b) explicit and detailed modeling by the teacher when applying the strategy being trained (Bandura, 1977); and (c) practical exercises in which the pupils were given the opportunity to use the strategy, first under guidance of the instructor, and subsequently, on their own (Brown \& Campione, 1994; Brown \& Palincsar, I984). The intervention sequence corresponding to sessions 2,3 , and 4 of the program, based on the strategies for main-idea identification via the application of macronules, are shown in the Appendix.

In accordance with the initial theoretical approach, our hypotheses were as follows: The treatment-group participants of both school-age levels would obtain significantly greater gains in the measures for the macrostructure construction and recall than participants from the control groups.

With regard to the macrostructure construction task: (a) Main-idea identification at the beginning of the text would be easier than elsewhere; and (b) main idea generalization would be more difficult than main idea selection independently of position.

Regarding the forescen developmental differences, the $10^{\text {th }}$-grade students would show superior results in the various measures of working memory, inference and comprehension, macrostructure construction, and recall than those of the $7^{\text {th }}$-grade students. In the treatment groups, developmental differences in the measures of macrostructure construction and recall would tend to decrease or disappear altogether.

We were also interested in examining the intercorrelations among the different measures of comprehension and inference, construction of the macrostructure and recall. We hypothesized that reading span, as a measure of working memory, should correlate positively with the rest of the measures. With this aim, we will confirm these intercorrelations at pretest, where they are not affected by the intervention.

With regard to the inference and comprehension tasks, we expected more time would be necessary for the response to be inferred from the implicit condition than from the explicit one. However, given the principle of immediacy, we did not predict any difference between the implicit and explicit conditions in the reading times for the third sentence.

\section{Method}

\section{Participants}

The participants were students at a standard middle-class school in Madrid. The inttial number of participants was 146, and after eliminating the dropouts, the final number was 110 . Experimental mortality rate was therefore relatively high (almost 25\%), although normal for this type of study.

Two treatment groups and two control groups were formed. In $7^{\text {th }}$ grade, there were 27 students in the treatment group and 36 in the control group. In tenth grade, there were 18 students in the treatment group and 29 in the control group. The mean ages were 12 years, 5 months $(S D=0.5)$ and 16 years, 2 months $(S D=0.6)$, respectively, for $7^{\text {th }}$. grade and $10^{\text {th }}$-grade students.

\section{Materials}

Reading span. A Spanish version of the Reading Span Task (Daneman \& Carpenter, 1980) was used. Participants had to read aloud a series of progressively longer phrases presented on the computer, and were then asked to recall the last word of each phrase. The level at which participants responded correctly on two out of three sets was taken as a measure of the individual's reading span

Inference and comprehension task. This task was also presented on the computer and consisted of three sentences describing some events and persons. In the third sentence, there was a pronominal reference to an element, which appeared either explicitly or implicitly in the preceding sentences. Readers were expected to construct a single mental model integrating the meaning of the three sentences. After having been presented with the three sentences, in an evaluation task, readers were asked what the element was (see Table 1). This anaphoral pronominal problem could thus be solved in two different ways. In the explicit condition, both the superficial information provided and the constructed semantic representation were available; this task could be considered a simple recognition task. On the other hand, in the implicit condition, participants were assumed to infer the response 
from the semantic representation and background knowledge (García Madruga et al., 1997). Although there was no superficial anaphoral antecedent in the implicit condition, participants could integrate the sentence in the previously constructed mental model. We registered the time taken by the participants to read each sentence and respond to the inference. The dependent variable was the reading-time of the target sentence in the implicit condition. Reading time integrates both the superficial decoding processes and the strictly semantic processes, because participants must pay attention to its meaning when reading the target sentence if they wish to respond correctly to the inference task. As regards the developmental changes, given the increase in practice and reading skills in adolescence, we expected a decrease in the reading time in the group of $10^{\text {th }}$-grade students.

Macrostructure construction tasks. Two macrostructure subtasks were presented, a main-idea identification task and a summarization task. In both cases, the response required the application of the selection and generalization macrorules. In the main-idea task, participants had to express the main idea of the text in one sentence. Four 5- to 7-line texts were used. Three of these texts explicitly included the main idea in different positions: at the beginning, in the middle, or at the end of the text. Participants therefore had to apply a simple selection macrorule to identify the main idea. The fourth text required participants to generalize the main idea.

In the summarization task, participants were asked to express briefly what they believed best summarized the content of the text. In this case, a longer text of about 15 lines was used. In order to carry out this task, participants had to apply two generalization macrorules and one selection mactorule.

Both for the main-idea task and the summary task, the same kind of measure was used. This measure evaluated the correctness of the participant's response compared to that established by the researchers, and which was determined by three judges. These judges were three of the researchers, who worked independently. Therefore, in the case of main ideas, we analyzed propositionally each of the criterion sentences, sub-dividing them into three propositions containing the predicate, the main clause, and a modifier. Kintsch's (1974) propositional analysis was used for this purpose (see Bovair \& Kieras, 1985). Two points were given for each of the first two propositions and one point for the proposition containing the modifier. Thus, the maximum score for this measure of the main-idea task was 5 points for each short text. For instance, supposing the main idea of one of the texts, by applying the selection macrorule was The population of South Africa is very unequally distributed by ethnic groups. This criterion sentence was analyzed as follows: 2 points for $P 1$ be distributed (population-South Africa P2); 2 points for $\mathrm{P} 2$ by ( $\mathrm{Pl}$ ethnic groups); and 1 point for $\mathrm{P} 3$ modify ( $\mathrm{P} 1$ unequally).

In the summary task, the same propositional analysis technique was used to obtain each participant's quantitative score, although the maximum possible score in this case was 6 points.

Recall task. The recall task consisted of reading a long text, "The Beginning of the Railroad in the United States" and a free recall test. Participants had to read and carefully study the text in order to remember it later. The text contained a rhetorical structure of "comparison-contrast," was 434 words long, and had 10 hierarchical levels. After studying the text, the students were requested to write down everything they could recall from it.

The recall measure was an author-developed molar procedure called "structural recall." The main feature of this measure is its administration ease. It also showed a high correlation with traditional macrostructural measures (García Madruga, Martín Cordero, Luque, \& Santamaría,

Table 1

\section{Example of the Material Used in the Comprehension and Inference Task}

1.a. Explicit condition: That Sunday morning Julia had oil heating up to make "churros" [fried noodles] while she waited impatiently for her son to arrive.

1.b. Implicit condition: That Sunday morning Julia was deep-frying "churros" while she waited impatiently for her son to arrive.

2. On the radio, they announced that there had been a terrible accident at the aitport when a plane was coming in to land.

3. Shocked by the alarming news, she made a sudden movement, spilling everything and burning herself.

\section{WHAT DID JULIA BURN HERSELF WITH?}

1. - with the flame

2. - with the frying pan

3. - with the oil 
1995). In this measure, the units no longer correspond to propositions in a strict sense, but rather to main ideas (semantically coherent complete sentences that express the macrostructure). Main ideas should be correctly recalled (internally coherent) in the appropriate scenario. The structural recall score is obtained by giving a point for each main idea recalled in the correct scenario, plus a point for each scenario recalled (e.g., if participants recalled 6 main ideas and 2 scenarios, the score would be 8 ). The concept of scenario was adopted from the comprehension theory of Sanford and Garrod (1981). The text used contained 10 main ideas and 3 scenarios, so that the maximum possible score for the structural recall measure was 13 points. The first scenario referred to topic approach, localization, and the goal of the text. It included the title and the first main idea. In the text employed, the first scenario referred to the conflicting opinions about the development of the railroad in the USA, some being in favor of and others against it. The second scenario had to do with characterization, motive, activities, and result of the group of persons who defended the railroad. It included main idea numbers $2,3,4$, and 5 . And the third scenario referred to the characterization and motives of the group of persons who were against the railroad. It included main idea numbers 6 to 10 .

\section{Procedure}

Both at pre- and posttest, participants carried out the various tasks in the same order. During an initial 45-minute session, they were given the reading-span task, presented on a computer, to do individually, and their responses were recorded on a cassette. Secondly, they carried out the inference and comprehension tasks, and lastly, the recall and comprehension tasks were carried out in groups, in a session lasting approximately 55 minutes (the usual class duration in Spanish schools).

Participants were given a booklet that contained six texts; four in the main-idea identification task, one in the summary task, and one in the free recall task. In the mainidea identification task, the four short texts were presented, in counter-balanced order (selection at the beginning, in the middle, and at the end, and generalization). All participants began with the four texts of the main-idea task and were allowed 4 minutes for each text. After reading the first text, they had 4 minutes to express the main idea in one sentence. Then, the experimenter asked them to read the second text, and so on, until they had read and processed all four texts. In the summary task, they were allowed 10 minutes to read the text carefully and to summarize its main ideas. Lastly, in the recall task, they were allowed 11 minutes to read and study the text. When the time was up, the experimenter collected the notebooks and, after a 3 minute informal chat, handed them a blank page on which, after writing down their personal data, they were asked to write down, during 12 minutes, everything they could remember from the text.

In the intervention phase, the participants in both the treatment groups were given instruction on main-idea identification and on drawing up outlines. The intervention was conducted by the researchers in eight 50-minute sessions in the classroom. None of the participants in either of the control groups received any type of intervention; they continued receiving their usual Spanish Language classes. Posttest was carried out five days after the end of the intervention and twenty days after pretest. (For further details of the program sessions, see García Madruga, Elosúa, Gutiérrez, Luque, \& Gárate, 1999).

\section{Design}

The design employed four groups with two treatment conditions (treatment and control) and two school-age levels ( $7^{\text {th }}$ and $10^{\text {th }}$ grades). The dependent variables were the scores in working memory, inference and comprehension, macrostructure construction, and recall measures, both at pre- and posttest. Each group consisted of an intact class, so the participants were not randomly assigned to the groups. However, the groups at each school-age level were randomly assigned to treatment conditions.

\section{Results}

Given the characteristics of the sample, non-parametric statistical tests were used. Pretest differences between the control and experimental groups at each school-age level were examined. There were no significant differences in any of the dependent variables.

Tables 2 and 3 show the pre- and posttest results obtained for the four main measures, at both school-age levels. In $7^{\text {th }}$-grade students (see Table 2), whereas in the control group, there was a gain only in the comprehension and inference measure (reading time) (using Wilcoxon's Test, $T=209, p$ $<.05$ ), in the experimental group, significant gains were observed in all the measures (reading span, $T=48, p<.01$; reading time, $T=77, p<.01$; macrostructure, $T=35, p<$ .01 ; and structural recall, $T=24.50, p<.01$ ). The same pattern was observed in the $10^{\text {th }}$-grade students (see Table 3 ). Whereas the control group obtained a gain only in reading time, $T=140, p<.05$, the experimental group showed significant gains in reading span, $T=6.50, p<.01$, reading time, $T=25, p<.01$, macrostructure, $T=23, p<.01$, and structural recall, $T=3.50, p<01$. In Table 4 are presented the differences in the gains between the control and experimental groups at both age levels. In reading span, inference, and comprehension measures, there were no significant gains in any of the groups, except for the reading span lest in the $7^{\text {th }}$ grade students (using the Mann-Whitney Test, $U=469, p<.05$ ). 
Table 2

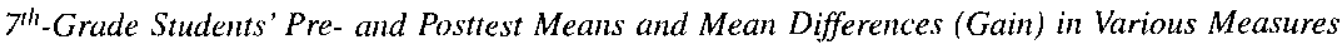

\begin{tabular}{|c|c|c|c|c|c|c|}
\hline \multirow[b]{2}{*}{ Variables } & \multicolumn{3}{|c|}{ Control Group $(n=36)$} & \multicolumn{3}{|c|}{ Experimental Group $(n=27)$} \\
\hline & $\begin{array}{c}\text { Pre-test } \\
\qquad M\end{array}$ & $\begin{array}{c}\text { Post-test } \\
M\end{array}$ & Gain & $\begin{array}{c}\text { Pre-test } \\
M\end{array}$ & $\begin{array}{c}\text { Post-test } \\
M\end{array}$ & Gain \\
\hline Reading Span & 2.97 & 2.99 & 0.02 & 2.68 & 2.97 & $0.29^{t i}$ \\
\hline Reading Time & 6.77 & 6.46 & $-0.31^{*}$ & 6.10 & 5.41 & $-0.69^{\dagger \dagger}$ \\
\hline Macrostructure & 2.66 & 2.71 & 0.05 & 2.58 & 3.48 & $0.90^{\dagger 1}$ \\
\hline Structural Recall & 5.86 & 6.44 & 0.58 & 4.70 & 7.92 & $3.22^{t+1}$ \\
\hline
\end{tabular}

* $p<.05$, two-tailed. ${ }^{\dagger \dagger} p<.01$, Wilcoxon's test, one- taited.

Table 3

$10^{\text {th }}$-Grade Students' Pre-and Posttest Means and Mean Differences (Gain) in Various Measures

\begin{tabular}{|c|c|c|c|c|c|c|}
\hline \multirow[b]{2}{*}{ Variables } & \multicolumn{3}{|c|}{ Control Group $(n=29)$} & \multicolumn{3}{|c|}{ Experimental Group $(n=18)$} \\
\hline & $\begin{array}{c}\text { Pre-test } \\
\quad M\end{array}$ & $\begin{array}{c}\text { Post-test } \\
M\end{array}$ & Gain & $\begin{array}{c}\text { Pre-test } \\
\qquad M\end{array}$ & $\begin{array}{c}\text { Post-test } \\
M\end{array}$ & Gain \\
\hline Reading Span & 2.93 & 3.28 & 0.35 & 2.92 & 3.32 & $0.40^{\dagger \dagger}$ \\
\hline Reading Time & 5.42 & 5.10 & $-0.32 *$ & 5.35 & 4.53 & $-0.82^{+t}$ \\
\hline Macrostructure & 3.45 & 3.37 & -0.08 & 3.19 & 3.77 & $0.58^{+t}$ \\
\hline Structural Recall & 9.48 & 10.03 & 0.55 & 9.89 & 12.00 & $2.11^{\dagger}$ \\
\hline
\end{tabular}

$* p<.05$, two-tailed. ${ }^{\dagger \dagger} p<.01$, Wilcoxon's test, one- tailed.

Table 4

Mean Differential Gains between Experimental and Control Groups in $7^{\text {th }}$ and $10^{\text {th }}$-Grade Students

\begin{tabular}{lccc}
\hline Variables & $7^{\text {th }}$ Graders $^{\mathrm{a}}$ & 10 $^{\text {th }}$ Graders $^{\mathrm{b}}$ & Total $^{\mathrm{c}}$ \\
& $n=63$ & $n=47$ & $N=110$ \\
\hline Reading Span & $0.27^{*}$ & 0.05 & 0.16 \\
Reading Time & -0.33 & -0.50 & -0.42 \\
Macrostructure & $0.85^{\dagger+}$ & $0.66^{+\dagger}$ & $0.78^{\dagger \dagger}$ \\
Structural Recall & $2.64^{\dagger+}$ & $1.56^{*}$ & $2.21^{\dagger \dagger}$
\end{tabular}

Note. "This measure was obtained by subtracting the $7^{\text {th }}$-grader control group's gain from the experimental group's gain (from Table 2).

b This measure was obtained by subtracting the $10^{\text {th }}$-grader control group's gain from the experimental group's gain (from Table 3).

c This measure is the mean differential gain of the experimental and control groups, independently of the students"grades.

$* p<.05$, two-tailed. ${ }^{\dagger+} p<.01$, Mann-Whitney's test, one-tailed.

A more detailed analysis of the intervention results can be seen from Tables 5 and 6 , which present the results of the macrostructure measures. As can be seen, the increments in both age groups are mainly due to improvement in the main-idea identification test, not in the summarization task. The $7^{\text {th }}$-grade students (see Table 5) improved their use of the selection rule for searching for the main idea at the beginning, $U=259, p<.01$, in the middle, $U=355.50, p$ $<.05$, and at the end, $U=211.50, p<.01$, but not in generalization, $U=444, p=.560$.
Although the $10^{\text {th }}$-grade students (see Table 6) showed significant improvement in application the selection rule to identify the main idea in the middle, $U=132.50, p<.01$, and at the end of the text, $U=171, p<.05$, as well as in applying the generalization rule, $U=189.50, p<.05$, no improvement was observed in the easiest selection rule, $U$ $=242, p=.678$.

As seen in Table 5, at pretest, taking into account the entire $7^{\text {th }}$-grade group (control and experimental groups), identifying the main idea at the beginning of the text $(M=$ 
Table 5

Pre-and Posttest Means and Differential Gains in Macrostructure Measures for $7^{\text {th }}$-Grade Students

\begin{tabular}{|c|c|c|c|c|c|}
\hline \multirow[b]{2}{*}{ Variables } & \multicolumn{2}{|c|}{$\begin{array}{c}\text { Control Group } \\
n=36\end{array}$} & \multicolumn{2}{|c|}{$\begin{array}{l}\text { Experimental Group } \\
\qquad n=27\end{array}$} & \multirow[b]{2}{*}{ Differential Gains } \\
\hline & $\begin{array}{c}\text { Pretest } \\
M\end{array}$ & $\begin{array}{c}\text { Posttest } \\
M\end{array}$ & $\begin{array}{l}\text { Pretest } \\
M\end{array}$ & $\begin{array}{c}\text { Posttest } \\
M\end{array}$ & \\
\hline Main-Idea Selection at Beginning & 3.47 & 3.22 & 3.3 .3 & 4.52 & $1.43^{t \dagger}$ \\
\hline Main-Idea Selection in Middle & 2.53 & 2.75 & 2.48 & 3.34 & $0.67^{*}$ \\
\hline Main-Idea Selection at End & 2.39 & 2.61 & 2.11 & 4.30 & $1.97^{4 i t}$ \\
\hline Main-Idea Generalization & 1.86 & 2.00 & 2.11 & 2.52 & 0.27 \\
\hline Summary & 3.03 & 2.97 & 2.85 & 2.70 & -0.09 \\
\hline Total Macrostructure & 2.66 & 2.71 & 2.58 & 3.48 & $0.85^{i k}$ \\
\hline
\end{tabular}

Note. a This measure is the difference between experimental and control groups in the posttest gains (which, in turn, were obtained by subtracting, for each group, the pretest means from its posttest means, and then subtracting the control group's gains from the experimental group's gains).

* $p<.05$, two-tailed. ${ }^{\dagger \dagger} p<.01$, Mann-Whitney's test, one-tailed.

Table 6

Pre- and Posttest Means and Differential Gains in Macrostructure Measures for $10^{t h}$-Grade Students

\begin{tabular}{|c|c|c|c|c|c|}
\hline \multirow[b]{2}{*}{ Variables } & \multicolumn{2}{|c|}{$\begin{array}{l}\text { Control Group } \\
\quad n=29\end{array}$} & \multicolumn{2}{|c|}{$\begin{array}{l}\text { Experimental Group } \\
\qquad n=18\end{array}$} & \multirow[b]{2}{*}{ Differential Gains ${ }^{a}$} \\
\hline & $\begin{array}{l}\text { Pretest } \\
\qquad M\end{array}$ & $\begin{array}{c}\text { Posttest } \\
M\end{array}$ & $\begin{array}{c}\text { Pretest } \\
M\end{array}$ & $\begin{array}{c}\text { Posttest } \\
M\end{array}$ & \\
\hline Main-Idea Selection at Beginning & 4.00 & 4.41 & 3.72 & 4.61 & 0.48 \\
\hline Main-Idea Selection in Middle & 4.00 & 3.79 & 3.83 & 4.61 & $0.99^{\text {tt }}$ \\
\hline Main-Idea Selection at End & 3.48 & 3.24 & 3.56 & 4.16 & $0.85^{*}$ \\
\hline Main-Idea Generalization & 2.59 & 2.41 & 2.11 & 2.72 & $0.78^{*}$ \\
\hline Summary & 3.17 & 2.97 & 2.72 & 2.72 & 0.21 \\
\hline Total Macrostructure & 3.45 & 2.37 & 3.19 & 3.77 & $0.66^{*+}$ \\
\hline
\end{tabular}

Note. ${ }^{a}$ This measure is the difference between experimental and control groups in posttest gains.

$* p<.05$, two-tailed. it $p<.01$, Mann-Whitney's test, one-tailed.

3.40) was easier than in the middle, $M=2.51, T=244, p$ $<.01$; at the end, $M=2.25, T=128, p<.01$; and than generalization, $M=1.99, T=163, p<.01$, (one-tailed, in all three cases). Generalization was significantly more difficult than identification in the middle of the text, $T=$ $498, p<.02$, one-tailed, but not than identification at the end of the text. Regarding posttest measurements, the control group's results were similar to their pretest. On the other hand, in the experimental group, due to the significant increment in main-idea identification at the end of the text, the differences between this measure and the identification at the beginning disappeared. All the remaining differences, namely between selection at the beginning and at the middle, $T=17, p<.01$, as well as between generalization and the three kinds of selection (at the beginning, $T=3, p<.01$; in the middle, $T=78, p<.01$, and at the end, $T=.00, p<$ .01 ; one-tailed, in all cases) were statistically significant.
As displayed in Table 6 , considering the entire $10^{\text {th }}$-grade group (experimental and control groups) at pretest, the differences between the different positions in main-idea identification seem to decrease: No significant differences were observed between main idea at the beginning ( $M=$ $3.86)$ and in the middle $(M=3.92, T=188, p=.980)$ or between main idea at the beginning and at the end $(M=$ 3.52, $T=180, p=.116)$, On the other hand, the generalization of the main idea $(M=2.35)$ was still significantly more difficult than identification at the beginning, $T=64, p<.01$; in the middle, $T=33.50, p<$ .01 ; and at the end, $T=74, p<.01$, (one-tailed, in all cases). At posttest, the following pattern of results for the control group was observed: Main-idea identification at the beginning was significantly easier than in the middle, $T=$ $25, p<.01$, and at the end, $T=16, p<.01$, one-tailed, in all cases), and generalization was significantly more difficult 
than main-idea identification at the beginning, $T=.00, p<$ .01 ; in the middle, $T=23.50, p<.01$; and at the end, $T=$ $29.50, p<.01$ (one-tailed, in all the cases). Differences between the middle and end positions were also statistically significant, $T=5.50, p<.01$, (one-tailed). In the experimental group, there were no statistically significant differences between main-idea identification at the beginning and in the middle of the text, $T=13, p=.866$, or between the latter and the end position, $T=5, p=.128$. However, the difference between the initial and end positions was statistically significant, $T=16.50, p<.05$ (one-tailed), as were the differences between the generalization of the main idea and its identification in any position (at the beginning, $T=.00, p<.01 ;$ in the middle, $T=3, p<.01$; at the end, $T=17.50, p<.01$, one-tailed, in all cases).

Regarding developmental results, as shown in Table 7 , except for reading span, the pretest differences were statistically significant in reading time, $U=1108, p<.01$; macrostructure $, U=.00, p<.01$; and structural recall, $U$ $=.00, p<.01$. At posttest for the control group, all contrasts were statistically significant: reading span, $U=392, p<$ .05 ; reading time, $U=359.50, p<.01$; macrostructure, $U$ $=286, p<.01$; and structural recall, $U=216.50, p<.01$ ). At posttest in the experimental group, reading span, $U=$ $156, p<.05$, and structural recall, $U=52.50, p<.01$, were the only statistically significant developmental results.
The intercorrelations are shown in Table 8 . As can be seen, in $7^{\text {th }}$ grade, all the intercorrelations were statistically significant, whereas in $10^{\text {th }}$ grade, only the intercorrelations between structural recall and the other three variables and the correlation between macrostructure and reading time reached statistical significance. There is a clear reduction in the intercorrelations with age.

\section{Discussion}

The results show the efficacy of our intervention program for the measures of macrostructure construction and structural recall. The improvement in reading span and reading-time measures can be considered the result of practice and motivation. Although practice had similar effects on both control and experimental groups, the latter might been more motivated. However, as seen in Table 4 , there were no statistically significant differential gains in any of these two measures between the experimental and the control group.

Our results confirm the first hypothesis about the efficacy of treatment for the macrostructure and construction and recall measures. Tables 2,3 , and 4 show that the increment in the macrostructure variable was significant for the experimental groups at both school-age levels. In structural recall, although improvement after the intervention in the

Table 7

Developmental Differences Between $7^{\text {hl }}$ and $10^{h /}$ Graders in Reading Span, Reading Time, Macrostructure, and Structural Recall

\begin{tabular}{|c|c|c|c|}
\hline Variables & $\begin{array}{l}\text { Pretest Differences } \\
\qquad N=110\end{array}$ & $\begin{array}{c}\text { Control Group } \\
\text { Posttest Differences } \\
\qquad n=65\end{array}$ & $\begin{array}{l}\text { Experimental Group } \\
\text { Posttest Differences } \\
\qquad n=45\end{array}$ \\
\hline Reading Span & 0.13 & $0.29 *$ & $0.35 *$ \\
\hline Reading Time & $-0.78^{\dagger \dagger}$ & $-1.62^{+\dagger}$ & $-0.88^{a}$ \\
\hline Macrostructure & $0.73^{\text {t十 }}$ & $0.66^{+t}$ & 0.29 \\
\hline Structura] Recall & $4.27^{1+}$ & $3.59^{\dagger+}$ & $4.07^{\text {材 }}$ \\
\hline
\end{tabular}

Note. In the first column, pretest developmental differences were obtained from four groups (Tables 2 and 3 ).

a $p<.10$, two-tailed. $* p<.05$, two-tailed. ${ }^{\dagger \dagger} p<.01$, Mann-Whitney's test, one-tailed.

Table 8

Spearman's Intercorrelations Between Various Pretest Measures, in $7^{\text {th }}$ and $10^{\text {th }}$ Graders

\begin{tabular}{|c|c|c|c|c|c|c|c|c|}
\hline \multirow[t]{2}{*}{ Pretest Measures } & \multicolumn{2}{|r|}{1} & \multicolumn{2}{|c|}{2} & \multicolumn{2}{|r|}{3} & \multicolumn{2}{|r|}{4} \\
\hline & $7^{t \mathrm{th}}$ & $/ 10^{\text {th }}$ & $7^{\text {th }} \quad /$ & $10^{\text {th }}$ & $7^{\text {th }}$ & $/ 10^{\text {th }}$ & $7^{\text {th }}$ & $/ 10^{\text {th }}$ \\
\hline \multicolumn{9}{|l|}{ 1. Reading Span } \\
\hline 2. Reading Time & $-.50^{\dagger \dagger}$ & $/ \quad .00$ & & & & & & \\
\hline 3. Macrostructure & $.36^{\text {t木 }}$ & $/ .20$ & $-.26^{*} /$ & $-.34^{\dagger+}$ & & & & \\
\hline 4. Structural Recall & $.50^{i t}$ & $/ .25 *$ & $-.46^{\dagger \dagger} /$ & $-.26 *$ & $.54^{ \pm \dagger}$ & $/ .25^{*}$ & & \\
\hline
\end{tabular}

$* p<.05$, two-tailed. ${ }^{+\dagger} p<.01$, one-tated. 
experimental groups was significant at both school-age levels, it was more significant and higher for $7^{\text {tl }}$-grade students than for $10^{\text {th }}$-grade students.

These results indicate that the intervention program was successful at both age levels. Younger participants increased their text-processing skills for main-idea identification, which in turn improved recall. The same pattern was found in older participants, except that the increment in the structural recall measure, although significant, was somewhat lower. A plausible explanation of this decrease in the $10^{\text {th }}$-grade students' gains is a possible ceiling effect. As observed in Table 3, at posttest, the structural recall means of this group was close to the maximum possible score (13).

In general, the intervention was more effective in tasks requiring the application of the selection macrorule than in tasks requiring generalization, as can be seen in Tables 5 and 6. In generalization, the benefits of the intervention are fewer, and this is especially clear in the case of the $7^{\text {th }}$-grade students, where the increase in main idea generalization did not reach significance. Likewise, it seems that the main-idea identification task was more sensitive to the intervention than the summary task, in which there was no statistically significant difference between the control and treatment groups. These two results are related, because in the mainidea identification task, participants must carry out three selections and only one generalization, whereas in the summary task, they must apply two generalizations and only one selection. Therefore, our intervention apparently did not achieve the desired results insofar as the generalization macrorule measures are concerned, as is particularly evident in the summary task.

The results shown in Tables 5 and 6 also confirm the second hypothesis concerning the differences between the various main-idea identification measures. Adolescents at both school levels tended to identify main ideas more easily at the beginning of the text, and the identification of main ideas by means of generalization tended to be more difficult. This result is seen more clearly in the efficacy of the intervention in the experimental group, which causes some differences between the main-idea identification at the beginning of the text and in other positions. Nevertheless, even after training, application of the selection rule continues to be the most difficult main-idea identification task, thus sirowing the limited effect of the intervention in this macrostrategy.

The instruction improved the application of a fairly simple strategy, requiring relatively low-level cognitive skills, such as selection. Brown and Day (1983) showed that macrorules could be ranked according to difficulty, as they require varying degrees of manipulation of the text contents. To this effect, the selection macrorule is easier to apply and appears earlier than does generalization (García Madruga, Gárate, Elosúa, Luque, \& Gutiérrez, 1997), thus making it more susceptible to instruction. Nevertheless, although we obtained the expected results for the lower school-age level, we had expected the intervention to produce better results for the generalization macrorule and summary task at the higher age level. Summary task deserves comment because the intervention in both age groups did not yield any increase in posttest measures. This clear lack of efficacy of the intervention makes us wonder whether the summary task might have some design defect, making it especially difficult. Students may also have found it more difficult to apply two macrorules (a selection rule and a gemeralization rule), at the same time and in relation to each other, in the same task - as in the case of the summary task- than to apply these macrorules separately to a text -as in the case of the main-idea identification task.

On the other hand, as mentioned, the data presented in Tables 5 and 6 suggest an interaction between the intervention and the school-age level. Thus, the efficacy of the intervention in the younger participants was more evident in the easier tasks, that is, main-idea identification at the beginning, in the middle, and at the end of texts; and no significantly different increase was found between the control and treatment groups in the most difficult task of main idea generalization. As for the older particjpants, the intervention was effective in identifying the main idea in the middle and at the end of the text, as well as in generalization, whereas in the easiest task (selection at the beginning), there were no posttest group differences.

The third hypothesis referred to developmental differences. As seen in Table 7 , the pretest results confirm this hypothesis as refers to reading time, macrostructure construction, and recall measures. Only reading span showed nonsignificant developmental differences between both the school-grade levels. However, developmental differences in the reading span measure were significant in posttest both in the control and the experimental groups. In the latter group, there was a posttest drop in developmental differences in reading time and macrostructure construction. Regarding macrostructure, this result is coherent with our expectations: Intervention usually icnds to eliminate or reduce developmental differences. This shows how intervention tends to equalize the participants, providing that it is sufficiently effective in reinforcing the most basic operations in macrostructure construction. This was not the case for reading time, where the differential effect of the intervention was unexpected.

In general, the $7^{\text {th }}$-grade students benefited more from the intervention, particularly in the macrostructure construction measures, than did the $10^{\text {th }}$-grade students. A possible explanation is that the $7^{\text {th }}$-grade students would have more room for improvement, whereas the $10^{\text {th }}$-grade students might have already acquired some of these strategies. This may explain why, in our study, contrary to some others (León \& Carretero, 1995; von der Weth \& Frankenburger, 1995), the "less competent readers" $\left(7^{\text {th }}\right.$ grade students) benefited more. 
The fourth hypothesis about the intercorrelations between the various measures was confirmed by the results. The students' text-comprehension skills, as measured by reading time and macrostructure-construction tasks, correlated significantly with their prior reading span and their subsequent free recall, particularly regarding the youngest participants. This shows the relationship between the different processes supported by cutrent theories in text comprehension, particularly Kintsch's (1998) theory.

As for the intercorrelations between reading span and the rest of measures, they are highly significant for the younger participants, whereas for older ones there is a tendency to diminish. This decreasing-with-age pattern is particularly clear in the case of the intercorrelation with reading time, which disappears, and could be interpreted in terms of increased practice and its subsequent automatization of underlying processes that thus cease to depend on working-memory resources. The same explanation was defended by Gathercole and Baddeley (1993, p. 228): "the developmental course of the relationship between the central executive and language understanding is therefore one of increasing independence as the child becomes more skilled at language processing". This is not the case of the recall measure, where the underlying processes continue to be related with working-memory capacity, as shown by the significant intercorrelation in $10^{\text {th }}$-grade students.

Regarding comprehension measures (reading time and macrostructure), they correlate at both school levels, even showing an increase with age. This result is in accordance with the idea that when reading a text, participants are carrying out some inferential processes similar to those involved in identifying main ideas. These common inferential processes probably consist of active scanning and manipulation of mental models of the situation described in the text, as some authors maintained years ago (Johnson-Laird, 1983; van Dijk \& Kintsch, 1983). Likewise, the intercorrelations between the two comprehension measures and structural recall shows the relationship between comprehension and recall at both school levels, although it decreases with age.

We would like to point out some of the limitations of our work, which should be taken into account in future studies. First, the duration of the effects of the intervention should have been checked. We did not take into account a measure of subsequent delay of the results of the intervention, which would have allowed us to verify the scope and stability of its effects on the different variables. Similarly, it would be advisable to use a learning-transfer measure of the active strategies to other kinds of situations.

\section{References}

Baker, L., \& Brown, A.L. (1984). Metacognitive skills and reading. In R. Barr, M.L. Kamil. \& P. Mosenthal (Eds.), Handbook of reading research. New York: Longman.
Bandura, A. (1977). Social learning theory. Englewood Cliffs, NJ. : Prentice-Hall.

Baumann, J.F. (1990). Teaching mean idea comprehension. Newark, NJ: International Reading Association.

Bovair, S. \& Kieras, D.E. (1985). A guide to propositional analysis for research on technical prose. In B,K. Britton \& J.B. Black (Eds.), Understanding exposifory text. A theoretical and practical handbook for analyzing explanatory text. Hillsdale, NJ: Erlbaum.

Britton, B.K., \& Graesser, A.C. (Eds.). (1996). Models of understanding text. Hillsdale, NJ: Erlbaum.

Brown, A.L., \& Campione, J.C. (1994). Guided discovery in a community of learners. In K. McGilly (Ed.), Classroom lessons: Cognitive theory and classroom practice (pp. 229-272). Cambridge, MA: MIT Press.

Brown, A.L., \& Day, J.D. (1983). Macrorules for summarizing texts: The development of expertise. Joumal of Verbal Leaming and Verbal Behavior, 22, 1-14.

Brown, A.L., \& Palincsar, A.S. (1984). Reciprocal teaching of comprehension strategies: A natural history of one program for enhancing learning. In J. Borbowski \& J.D. Day (Eds.), Intelligence and cognition in special children: Comparative studies of giftedness, mental retardation and learning disabilities. New York: Ablex.

Cantor, J., Engle, R.W., \& Hamilton, G. (1991). Short-term memory, working memory, and verbal abilities: How do they relate? Intelligence, 15, 229-246.

Daneman, M., \& Carpenter, P.A. (1980). Individual differences in working memory and reading. Joumal of Verbal Leaming and Verbal Behavior, 19, 450-466. [Spanish version: Elosúa, M.R., Gutiérrez, F., García Madruga, J.A., Luque, J.L. \& Gárate, M. (1996). Adaptación española del "Reading Span Task," de Daneman y Carpenter. Psicothema, 2, 383-395.]

De Beni, R., Palladino, P., Pazzaglia, F., \& Cornoldi, C. (1998). Increases in intrusion errors and working memory deficit of poor comprehenders. The Quarterly Journal of Experimental Psychology, 2, 305-320.

Ericsson, K.A., \& Kintsch, W. (1995). Long-term working memory. Psychological Review, 102, 211-245.

García Madruga, J.A., Elosúa, M.R., Gutiérrez, F., Luque, J.L., \& Gárate, M. (1999). Comprensión lectora y memoria operativa. Aspectos evolutivos e instruccionales. Barcelona: Paidós.

García Madruga, J.A., Gárate, M., Elosúa, M.R., Luque, J.L., \& Gutiérrez, F. (1997). Comprensión lectora y memoria operativa: un estudio evolutivo. Cognitiva, 1, 99-132.

García Madruga, J.A., Martín Cordero, J.I., Luque J.L., \& Santamaría, C. (1995). Comprensión y adquisición de conocimientos a partir de textos. Madrid: Siglo XXI.

Gathercole, S.E., \& Baddeley, A.D. (1993). Working mentory and language. Hillsdale, NJ: Erlbaum.

Johnson-Laird, P.N. (1983). Mental models. Towards a cognitive science of language, inference and consciousness. Cambridge, MA: Harvard University Press.

Just, M.A., \& Carpenter, P.A. (1992). A capacity theory of comprehension: Individual differences in working memory. Psychological Review, I, 122-149. 
Kintsch, W. (1974). The representation of meaning in memory Hillsdale, NJ: Erlbaum.

Kintsch, W. (1988). The role of knowledge in discourse comprehension: A construction-integration model. Psychological Review, 2, 163-182.

Kintsch, W. (1998), Comprehension. A paradigm for cognition. Cambridge, MA: Cambridge University Press.

Kintsch, E., \& Kintsch, W. (1995). Strategies to promote active learning from text: Individual differences in background knowledge. Swiss Journal of Psychology, 2, 141-151.

Kintsch, W., \& van Dijk, T.A. (1978). Towards a model of text comprehension and production. Psychological Review, 85, 363394.

Kurtz, B.E. (1991). Cognitive and metacognitive aspects of text processing. In G. Denhière \& J.P. Rossi (Eds.), Text and text processing (pp.77-103). Amsterdam: North-Holland.

León, J.A., \& Carretero, M. (1995). Intervention in comprehension and memory strategies: Knowledge and use of text structure. Learning and Instruction, 5, 203-220.

McKeown, M.G., Beck, I.L., Sinatra, G.M., \& Loxterman, J.A. (1992). The contribution of prior knowledge and coherent text to comprehension. Reading Research Quarterly. 27, 7893.

McNamara, D.S., \& Kintsch, W. (1996). Learning from text: Effect of prior knowledge and text coherence. Discourse Processes; $22,247-288$.
McNamara. D.S., Kintsch, E., Songer, N.B., \& Kintsch, W. (1996). Are good texts always better? Text coherence, background knowledge, and levels of understanding in learning from text. Cognition and instruction, 14, 1-43.

Piolat, A., \& Roussey, J.Y. (1996). Students'drafting strategies and text quality. Learning and Instruction, 2, 111-129.

Roehler, L.R., \& Duffy, G.G. (1984). Direct explanation of comprehension processes. In G.G. Duffy. L.R. Roehler, \& J. Mason (Eds.), Comprehension instruction: Perspectives and suggestions. New York: Longmans Green.

Sanford, A.S., \& Garrod, C.J. (1981). Understanding written language. New York: Wiley.

van Dijk, T.A., \& Kintsch. W. (1983). Strategies of discourse comprehension. New York: Academic Press.

van Oostendorp, H., \& Goldman, S.R. (Eds.). (1999). The construction of mental representations during reading. Mahwah, NJ: Erlbaum.

Volet, S.E. (1997). Cognitive and affective variables in academic learning: The significance of direction and effort in students"goals. Leaming and Instruction, 3, 235-254.

von der Weth, R., \& Frankenberger, E. (1995). Strategies, competence and style-problem solving in engineering design. Learning and Instruction, 5, 357-383.

Received April 2, 2001

Revision received January 31, 2002

Accepted March 8, 2002 
APPENDIX

Intervention Sequence: Sessions 2, 3, and 4.

\begin{tabular}{|c|c|c|c|}
\hline Session & Texts & Aims and contents & General procedure \\
\hline 2 & $\begin{array}{l}\text { Short texts (single paragraph of } \\
4-5 \text { sentences) with the Main } \\
\text { Idea (MI) at the beginning, in } \\
\text { the middle, and at the end. }\end{array}$ & $\begin{array}{l}\text { Awareness of the various macrostrategies } \\
\text { available for summarizing a paragraph. } \\
\text { Selective and flexible } \\
\text { application of the MI } \\
\text { Selection macrorule. }\end{array}$ & $\begin{array}{l}\text { - Verbal instruction with examples. } \\
\text { - Text presentation (texts } 2.1,2.2, \text { and } 2.3 \text { ). } \\
\text { - Exercise: Identify MI. } \\
\text { - Discussion and comparison. } \\
\text { - Modeling the strategy application. } \\
\text { - Guided practice and feedback. } \\
\text { - Individual practice and feedback. }\end{array}$ \\
\hline 3 & $\begin{array}{l}\text { Short texts (single paragraph of } \\
4-5 \text { sentences) with the MI not } \\
\text { explicitly expressed. }\end{array}$ & $\begin{array}{l}\text { Selective and flexible } \\
\text { application of the MI Generalization } \\
\text { and Construction macrorules. }\end{array}$ & $\begin{array}{l}\text { Same procedure, with texts } 2.4,2.5 \text {, and } 2.6 \text { for } \\
\text { Generalization macro-strategy, and texts } 2.7,2.8 \text {, } \\
\text { and } 2.9 \text { for Construction macrostrategy }\end{array}$ \\
\hline 4 & Longer text: "The Cheyenne" & $\begin{array}{l}\text { - Give a suitable title to the text. } \\
\text { - Select or write up the MIs of text. } \\
\text { - Metacognitive skill: comprehension } \\
\text { self-assessment. }\end{array}$ & $\begin{array}{l}\text { - Text presentation (text } 3 \text { ). } \\
\text { - Suggestion of titles. Discussion. } \\
\text { - List of MIs. Discussion. } \\
\text { - Modeling. Four rules for active text processing: } \\
\text { 1. Note the rhetoric signs and markers. } \\
\text { 2. Attempt to visualize what is described. } \\
\text { 3. Ask the text questions. } \\
\text { 4. Re-read to improve understanding. } \\
\text { - Self-scoring of work, checking right and wrong } \\
\text { answers (comparing own list of MIs with that } \\
\text { of instructor). }\end{array}$ \\
\hline
\end{tabular}

